El tabaco y la esclavitud en la rearticulación imperial ibérica (s. xv-xx)

Publicações do Cidehus

\title{
Uma revolução de escala? O impacte do estanco no comércio de tabaco brasileiro
}

(Lisboa, primeira metade do século XVIII)

\section{João Paulo Salvado}

DOI: 10.4000/books.cidehus. 6141

Editora: Publicações do Cidehus

Lugar de edição: Évora

Ano de edição: 2018

Online desde: 11 Janeiro 2019

coleção: Biblioteca - Estudos \& Colóquios

ISBN eletrónico: 9791036531132

\section{Qbooks}

http://books.openedition.org

\section{Refêrencia eletrónica}

SALVADO, João Paulo. Uma revolução de escala? O impacte do estanco no comércio de tabaco brasileiro: (Lisboa, primeira metade do século XVIII) In : El tabaco y la esclavitud en la rearticulación imperial ibérica (s. Xv-xx) [en ligne]. Évora : Publicações do Cidehus, 2018 (généré le 06 mai 2019). Disponible sur Internet : <http://books.openedition.org/cidehus/6141>. ISBN : 9791036531132. DOI : 10.4000/ books.cidehus.6141. 
Uma revolução de escala? O impacte do estanco no comércio de tabaco brasileiro (Lisboa, primeira metade do século XVIII)*

\section{João Paulo Salvado**}

\section{Resumo}

Este capítulo examina as alterações ocorridas no comércio de importação de tabaco na primeira metade do século XVIII e explora o papel do estanco português do tabaco nesse fenómeno. Na ausência de livros alfandegários, oito Livros de Entrada de tabaco em bruto na fábrica de Lisboa constituem a base empírica para observar a concentração da importação num número mais reduzido de agentes entre 1710-1737. A contratação da exploração do estanco por consórcios mercantis a partir de 1702 recebe aqui um olhar atento enquanto vector com potencial explicativo. Constata-se que a integração vertical do fornecimento, introduzida em 1722 e depois sistematicamente prosseguida, produziu impactes duradouros na actividade de importação e nos seus agentes. Todavia, a concentração dos negócios no comércio de tabaco foi acompanhada por um fenómeno de volatilidade entre os maiores importadores, o que contrasta com o caso inglês, estudado por Price e Clemens.

\section{Palavras-chave}

importadores, concentração de mercado, arrendamento fiscal, integração vertical, inovação organizativa

\section{Abstract}

This chapter examines the changes that the Portuguese tobacco trade underwent in the first half of the eighteenth century and explores the role played the tobacco monopoly in explaining those changes. Based on eight purchase day books of the Royal Tobacco Factory of Lisbon, it showcases a decline in the number of importers between 1710

\footnotetext{
* Este texto foi elaborado no âmbito do projecto de investigação «La configuración de los espacios ibéricos. De políticas imperiales a políticas nacionales en torno al tabaco. Siglos XVII-XIX» (HAR 2015-66142R), e da bolsa de pósdoutoramento da Fundação para a Ciência e a Tecnologia (Portugal) (POPH/FSE (EC) SFRH/BPD/88967/2012). Integra também o projecto CIDEHUS - UID/HIS/00057/2013 (POCI-01-0145-FEDER-007702), FCT, COMPETE, FEDER, Portugal 2020.

** CIDEHUS, Universidade de Évora
} 
and 1737 and focuses on the farming of the tobacco monopoly by private partnerships as an explanatory variable. It concludes that the vertical integration of the supply chain, first introduced in 1722 and routinely implemented from then on, had a long lasting impact on the importers. However, the concentration of imports in a smaller number of importers was accompanied by a high degree of volatility among the largest importers, which stands in contrast with the trends noted by Price and Clemens for the English tobacco trade.

\section{Keywords}

importers, market concentration, tax-farming, vertical integration, organizational change

\section{Introdução}

No século XVIII o comércio intercontinental per capita cresceu exponencialmente, sobretudo entre as cinco maiores potências coloniais (Inglaterra, Holanda, Espanha, Portugal e França), tal como a literatura recente tem constatado. ${ }^{1}$ Esta tendência macroeconómica cruza-se com uma outra constatação historiográfica, esta mais centrada nos portos e nos agentes mercantis envolvidos no comércio transatlântico, segundo a qual entre 1700 e 1800 estiveram em marcha fenómenos de concentração e especialização portuária, acompanhados de uma diminuição do número de agentes e sua especialização funcional. A especialização dos portos transatlânticos na Inglaterra desta centúria é bem conhecida, enquanto as transformações que ocorreram no universo dos operadores que lidavam com produtos coloniais foi estudada por Nuala Zahedieh, para Londres, e por Jacob Price e Paul Clemens para o caso do tabaco. ${ }^{2}$ Estes últimos autores identificaram uma revolução de escala no comércio do tabaco, que se traduziu na redução e consolidação das casas tabaqueiras, e cujo momento de viragem se situa nos finais do século XVII. Na explicação deste fenómeno os autores combinam razões de ordem institucional e económica, materializadas na elevação dos direitos aduaneiros, maior

1 COSTA, Leonor Freire; PALMA, Nuno; REIS, Jaime, «The Great Escape? The Contribution of the Empire to Portugal's Economic Growth, 1500-1800», in European Review of Economic History, vol. 19, n. ${ }^{\circ}$ 1, 2015, pp. 1-22; ALLEN, Robert C., «Poverty and Progress in Early Modern Europe», in The Economic History Review, vol. 56, n. ${ }^{\circ} 3,2003$, pp. 403-443.

2 Para os portos ingleses, vejam-se MORGAN, Kenneth, «Bristol and the Atlantic Trade in the Eighteenth Century», in The English Historical Review, vol. 107, n. ${ }^{\circ} 424$, 1992, pp. 626-650; Idem, Bristol and the Atlantic Trade in the Eighteenth Century, Cambridge, Cambridge University Press, 2004, pp. 222-223; para o caso de Londres ZAHEDIEH, Nuala, The Capital and the Colonies: London and the Atlantic Economy, 1660-1700, Cambridge, Cambridge University Press, 2010; e para o tabaco PRICE, Jacob M.; CLEMENS, Paul G. E., «A Revolution of Scale in Overseas Trade: British Firms in the Chesapeake Trade, 1675-1775», in The Journal of Economic History, vol. 47, n. ${ }^{\circ}$ 1, 1987, pp. 1-43. 
regulação pelo Estado e numa maior disponibilidade de crédito que se repercutiu numa utilização mais eficiente do transporte marítimo.

Se em Portugal também já se constatou o crescimento per capita do comércio intercontinental, mais acentuado na primeira metade de 1700 do que na segunda, os impactes deste fenómeno no universo dos agentes mercantis, seja na dimensão do grupo, seja na dimensão das firmas e na concentração de negócios, são melhor conhecidos para as décadas pós-1760, mercê da monografia de Jorge Pedreira sobre a praça de Lisboa. ${ }^{3}$ A primeira metade da centúria gera ainda interrogações, muito embora seja certo que o ciclo mineiro trouxe estímulos que impactaram na comunidade mercantil portuguesa que operava a partir de Lisboa. O número de negociantes envolvidos nos tratos coloniais aumentou por meio de novos membros, cuja entrada no grupo era favorecida pela inexistência de barreiras de acesso e pelo regime de livre concorrência em que se realizava o comércio colonial luso-atlântico. ${ }^{4}$

Com início ainda em meados de 1600, o crescimento do volume do comércio do tabaco brasileiro foi acompanhado pelo aumento do número dos operadores, como já o demonstrou Leonor Freire Costa, usando como base empírica dados das importações de tabaco na cidade do Porto para os anos de $1639-1657 .{ }^{5}$ Em linha com o aumento da procura europeia, os dados coligidos mostram uma tendência comum àquela verificada para Londres e outros portos ingleses neste período, na medida em que revelam um forte envolvimento de pequenos negociantes no comércio de tabaco, muito embora não se possa falar de especialização. ${ }^{6}$ Para Lisboa, porto obrigatório de partida e chegada da navegação transatlântica desde 1649, não há registos alfandegários que permitam conhecer os operadores do comércio colonial e a respectiva repartição das importações para período anterior a 1756. Todavia, a aquisição de tabaco para a real fábrica de Lisboa,

3 PEDREIRA, Jorge, Os Homens de Negócio da Praça de Lisboa de Pombal ao Vintismo: Diferenciação, reprodução e identificação de um grupo social, Lisboa, Dissertação de Doutoramento em Sociologia, Faculdade de Ciências Sociais e Humanas da Universidade Nova de Lisboa, 1995, pp. 125-154. Vejam-se ainda PEDREIRA, Jorge, «Os Negociantes de Lisboa na Segunda Metade do Século XVIII: Padrões de recrutamento e percursos sociais», in Análise Social, vol. 27, n. ${ }^{\text {os }}$ 116-117, 1992, pp. 407-440; e Idem, «Tratos e Contratos: Actividades, interesses e orientações dos investimentos dos negociantes da praça de Lisboa, 1755-1822», in Análise Social, vol. 31, n. ${ }^{\text {os } 136-137, ~ 1996, ~ p p . ~ 335-379 . ~}$

4 Este é um dos temas centrais do meu projecto «A Elite Mercantil de Lisboa na Primeira Metade do Século XVIII: caracterização social e económica», financiado pela FCT (SFRH/BPD/88967/2012), em curso. Veja-se SALVADO, João Paulo, «The Rise and Fall of a Lisbon Family Business, 1710-1773: The Case of the House of Torres», Itinerario: International Journal on the History of European Expansion and Global Interaction, vol. 43, n. ${ }^{\circ}$ 1, 2019 (no prelo).

5 COSTA, Leonor Freire, «Os Primórdios do Tabaco Brasileiro: Monopólios e Expansão do Mercado, 1600-1700», in LUXÁN, Santiago de (dir.), Política y Hacienda del Tabaco en los Impérios Ibéricos (siglos XVII-XIX), Madrid, Centro de Estudios Políticos y Constitucionales, 2014, pp. 40-41.

6 ZAHEDIEH, The Capital and the Colonies, p. 57. 
ao abrigo do estanco doméstico, oferece uma fonte alternativa para observar o universo dos importadores de tabaco que operavam a partir da capital do reino e do império. ${ }^{7} \mathrm{Na}$ verdade, a forte regulação que a Junta da Administração do Tabaco impôs ao estanco depois de 1674 produziu fontes quantitativas que permitem também uma aproximação ao comércio do tabaco e os seus operadores.

Entre elas, contam-se os Livros de Entrada de tabaco em bruto na fábrica que constituem a base empírica na qual se sustenta este estudo. Desta colecção usaram-se os oito livros relativos ao período que se estende de 1710 a 1737, por conterem informações nominais sobre os proprietários do tabaco comprado para o estanco doméstico e as quantidades vendidas, podendo, pois, servir de lente de observação dos protagonistas deste comércio, bem como da estrutura da importação, tomada a partir da repartição do fornecimento. A escolha deste arco temporal impôs-se pelas características desta colecção que não chegou completa aos nossos dias, bem como pelos objectivos que norteiam este texto. Se existem alguns livros dispersos desta série para os finais do século XVII, o primeiro livro que chegou até nós produzido no âmbito da exploração privada do estanco por consórcios mercantis data apenas do triénio 1710-1712. Por seu turno, 1737 representa o fim de um sistema de notação que, nos anos subsequentes deixará de reter os nomes dos fornecedores à fábrica. Aqui se ensaia, pois, uma primeira sistematização e análise dos dados relativos a estes anos.

Este texto prossegue um duplo objectivo. O primeiro procura sondar a estrutura do fornecimento à fábrica e detectar eventuais alterações na distribuição por fornecedor/importador que tenham ocorrido nesta cronologia. $\mathrm{O}$ inquérito que lhe subjaz orienta-se, pois, no sentido de determinar se há indícios de concentração dos negócios nas mãos de um número mais reduzido de negociantes envolvidos no comércio do tabaco, tal como detectado por Price e Clemens para o caso da Inglaterra. Partindo da constatação que o comércio de importação em Portugal, embora sendo livre e aberto a todos os naturais, estava sujeito a um conjunto de constrangimentos decorrentes do monopólio doméstico de venda de tabaco, o segundo objectivo indaga o impacte que a administração indirecta do estanco teve no comércio de importação e nos seus agentes. A contratação da

7 Atendendo ao escopo deste texto, o comércio de tabaco que ligava directamente os portos brasileiros e África e os seus agentes não são aqui objecto de análise. Sobre este assunto, vejam-se NARDI, Jean-Baptiste, O Fumo Brasileiro no Período Colonial: Lavoura, Comércio e Administração, São Paulo, Brasiliense, 1996, pp. 203-261; SCHWARTZ, Stuart, «The Colonial Brazil, c. 1580-1750: Plantations and Peripheries», in BETHEL, Leslie (ed.), Colonial Brazil, Cambridge, Cambridge University Press, 1987, pp. 100-104. 
exploração do estanco por consórcios mercantis a partir de 1702 recebe aqui um olhar mais atento enquanto variável explicativa em mudanças ocorridas na importação no caso português, sem prejuízo do concurso de outras variáveis, como flutuações dos preços de aquisição ao produtor e de venda para reexportação, taxas aduaneiras, custos do transporte marítimo e flutuações dos mercados de procura que, todavia, aqui não irão ser exploradas. Dito de outro modo, este texto visa sondar se a revolução de escala notada por Price e Clemens também se observou em Portugal e saber até que ponto a variável estanco doméstico, ausente em Inglaterra onde a fiscalidade sobre o tabaco assentou apenas em taxas aduaneiras, e a sua administração indirecta produziram impactes significativos no comércio do tabaco e seus operadores.

Estes objectivos concretizam-se nos pontos subsequentes. O primeiro discute os constrangimentos institucionais e normativos ditados pelo estanco e pelo regime de contratação privada que perdurou até ao século XIX, antes de sistematizar os dados dos Livros da Entrada da Fábrica, onde se constata uma mudança ocorrida em 1722. O último ponto contextualiza essa viragem à luz das opções de gestão introduzidas pelo consórcio holandês que à data geria o monopólio do tabaco.

\section{Contexto normativo e institucional}

A importação de tabaco brasileiro na primeira década do século XVIII inscrevia-se no quadro de uma dupla moldura normativa e institucional definida, por um lado, para o comércio colonial atlântico e, por outro, para o estanco metropolitano do tabaco. Talvez mais do que em qualquer outro produto colonial, os agentes envolvidos no comércio de trazida de tabaco estavam fortemente condicionados por regras impostas pela monarquia. Antes de mais, o regime de frotas, instituído em 1649, impunha um calendário de navegação no Atlântico, ao mesmo tempo que forçava a circulação por Lisboa, doravante porto obrigatório nos fluxos mercantis que ligavam os dois lados do oceano. ${ }^{8}$ Ademais, a rigidez deste calendário ajustava-se mal ao ciclo produtivo da planta, potenciando os riscos de perda decorrentes da sua insuficiente maturação e mau acondicionamento para a viagem. ${ }^{9}$ Os maiores constrangimentos à livre actuação dos agentes provinham, todavia, das disposições do estanco doméstico do tabaco, mormente da sua complexa moldura normativa e institucional implementada depois de 1674.

8 COSTA, Leonor Freire, O Transporte no Atlântico e a Companhia Geral do Comércio, 1580-1663, vol. 1, Lisboa, Comissão Nacional para as Comemorações dos Descobrimentos Portugueses, 2002; PEDREIRA, Os Homens de Negócio, pp. 53-61.

9 NARDI, Jean-Baptiste, O Fumo Brasileiro, pp. 116-117. 
Vale a pena recordar que, no reino de Portugal o estanco foi concebido como um exclusivo de transformação e de venda de tabaco brasileiro no espaço metropolitano e nas ilhas da Madeira e dos Açores. Instituído por volta de 1634, ainda no contexto de pressão fiscal dos Habsburgo espanhóis, o estanco entrou numa nova fase da sua história em 1674, quando se inaugurou o modelo institucional que, com poucas alterações perduraria até ao século XIX. ${ }^{10}$ Tinha como propósito uma maior intervenção da coroa na regulação e supervisão do exclusivo e traduziu-se na criação da Junta da Administração do Tabaco, organismo encarregue, entre outras funções, de supervisionar a cobrança fiscal. Sob a sua jurisdição, a Alfândega do Tabaco e os Armazéns do Tabaco (Armazém Grande e Armazéns do Jardim) criaram-se pouco depois, introduzindo novos procedimentos destinados a controlar os fluxos de entrada e saída de tabaco brasileiro no espaço metropolitano. A elas se veio juntar a constituição de uma manufactura real em Lisboa, para centralizar a transformação do tabaco em rolo, em pó e folha e controlar a intermediação da sua venda por grosso. O trespasse para particulares da exploração da transformação e venda do tabaco por meio de contratos trienais a partir de 1702 não veio alterar substantivamente este modelo institucional. Consequentemente, a Junta da Administração do Tabaco manteve a sua função de supervisora do estanco. ${ }^{11}$ As implicações deste quadro institucional e da gestão privada do estanco para os agentes do comércio colhem-se da observação do circuito descrito pelo tabaco antes de ser lançado no mercado doméstico ou de ser encaminhado para a reexportação. O circuito que aqui se descreve cruza as normas introduzidas, em 1702, pelo regimento da Alfândega do Tabaco com os estilos quotidianos, testemunhados pela documentação coeva que chegou aos nossos dias. $^{12}$

Chegadas as frotas e sob a supervisão dos oficiais da Junta, o tabaco era descarregado e levado para a Alfândega, onde os volumes (rolos, fardos, sacas, maçarocas e canastras) se contavam e confrontavam com o manifesto de carga, antes de serem encaminhados para o

10 Sobre este assunto, veja-se SALVADO, João Paulo, «O Estanco do Tabaco em Portugal: Contrato-geral e Consórcios Mercantis, 1720-1755», in LUXÁN, Santiago de (dir.), Política y Hacienda del Tabaco en los Imperios Ibéricos, Siglos XVII-XIX, Madrid, Centro de Estudios Políticos e Constitucionales, 2014, pp. 137-144.

11 Sobre a mudança do modelo de administração que ocorre em 1702, veja-se SALVADO, «Estanco do Tabaco em Portugal», pp. 142-144.

12 «Do que se há de observar na alfândega» in Regimento da Junta da Administração do Tabaco, de 18 de Outubro de 1702 publicado por SOUSA, José Monteiro de Campos Coelho e, Systema ou Collecção dos Regimentos Reaes, tomo IV, Lisboa, Na Officina de Simão Thaddeo Ferreira, 1785, pp. 29-35. 
Armazém Grande. ${ }^{13}$ Aqui se reuniam os donos das partidas e os potenciais compradores para ajustarem os negócios, muito embora o exame do tabaco só pudesse ser feito mediante autorização prévia do provedor da alfândega e na presença dos guardas do Jardim. Ao abrigo da primazia de escolha que o contrato atribuía ao contratador-geral, este último podia examinar e escolher os lotes que pretendesse adquirir sem a presença do proprietário. Só depois de exercido este direito de preferência, que incluía a aquisição à revelia, podiam os proprietários ajustar-se com os reexportadores. Decidido o destino final do tabaco, procedia-se ao despacho alfandegário. ${ }^{14}$ Nessa ocasião, o tabaco conduzia-se do Armazém Grande à Alfândega, onde só então se pesavam os volumes para a dedução de direitos de entrada ou de saída. Apurados os direitos aduaneiros, o tabaco saía finalmente do Armazém Grande, prefigurando-se três possíveis destinos: a fábrica de Lisboa, o embarque directo num navio para uma qualquer escápula europeia, ou ainda o seu re-armazenamento, desta feita, nos Armazéns do Jardim, antes que uma das outras duas hipóteses se pudesse concretizar. ${ }^{15}$

O estanco doméstico condicionava ainda a actividade dos agentes mercantis de uma outra forma, desta feita enquanto regime de preços administrados, com interferência na sua capacidade de gerar mais-valias. A regulação dos preços pela monarquia, seja no produtor, seja no fornecimento ao estanco, insere-se num contexto específico, marcado pelo prenúncio da Guerra de Sucessão de Espanha e pela necessidade de se cobrar um donativo de 640.000.000 de réis anuais, parte da qual se pretendia obter do monopólio de venda do tabaco. ${ }^{16}$ Entre 1698 e 1701, estabeleceram-se os termos essenciais do tabelamento de preços com efeitos no comércio de trazida, sendo que na cronologia da legislação se surpreende uma preocupação constante por parte da monarquia em conciliar os seus interesses fiscais com os interesses de produtores brasileiros e dos importadores,

13 Note-se que a Alfândega e os Armazéns do Jardim eram espaços contíguos. Nos termos do regimento da alfândega, os volumes de tabaco deveriam ser pesados à entrada da alfândega, antes de serem conduzidos ao Armazém Grande. Todavia, este procedimento não parece ter sido observado, provavelmente porque a pesagem de 20 a 25 mil rolos de tabaco chegados nas frotas do Brasil seria uma tarefa incompatível com os meios humanos e as infra-estruturas existentes e com o curto espaço de tempo disponível para armazenar o tabaco («Do que se há de observar na alfândega», in Systema ou Colecção dos Regimentos Reais, cap. 8, pp. 30-31).

14 Vale a pena sublinhar que esta etapa tardia do despacho alfandegário no caso do tabaco se deve inteiramente ao estanco, e que diverge do que estava em uso para qualquer outro produto.

15 «Do que se há de observar na alfândega», in Systema ou Colecção dos Regimentos Reais, caps. 1-26, pp. 29-35; e ainda Lisboa, Biblioteca Nacional de Portugal, Códice 235, fls. 10-42v .

16 Recorde-se que este donativo foi pedido nas Cortes de 1697-1698 e destinava-se a reforçar o contingente militar do reino (SALVADO, «O Estanco do Tabaco em Portugal», pp. 141-143). 
num exercício de economia política imperial. ${ }^{17}$ Nesse sentido, o preço da venda de tabaco ao estanco fixou-se em 120 réis a libra em finais de 1698, medida que visava proteger o estanco de flutuações especulativas da matéria-prima. Mal recebida pelos importadores, por decreto de 4 de Março de 1699 o preço da libra de matéria-prima foi novamente tabelado em 140 réis para o tabaco de primeira qualidade e em 130 para o de segunda categoria, valores que se mantiveram inalterados até meados do século. Dois anos volvidos, a monarquia acomodou novamente os interesses dos agentes mercantis ao estabelecer um preço máximo do tabaco adquirido ao fornecedor, fixado em 1.200 réis a arroba, ou seja, 37,5 réis a libra. ${ }^{18}$ A medida causou um profundo mal-estar entre os produtores de tabaco no Brasil e, na prática, os preços de aquisição da matéria-prima acabaram por obedecer às leis do mercado. De acordo com os dados avançados por JeanBaptiste Nardi, até 1739, os preços de venda de tabaco no Brasil estiveram sempre muito além do tecto fixado pela monarquia, em detrimento dos interesses dos negociantes. ${ }^{19} \mathrm{O}$ regime de preços administrados só não se estendia à actividade de reexportação, governada pelas leis da oferta e da procura.

Se o monopólio doméstico de venda constituiu a principal fonte de receita fiscal proveniente do tabaco, há que não esquecer que este produto oferecia também taxas aduaneiras, cobradas na Alfândega do Tabaco. No quadro de um sistema alfandegário em que se onerava sobretudo o movimento de entrada, cabia aos responsáveis pela trazida o pagamento dos direitos de importação. Também neste âmbito a Guerra de Sucessão de Espanha marcou uma subida acentuada dos direitos de entrada, fixados em 1.600 réis a arroba (50 réis a libra), valor que se cobrou entre 1701 e 1713. Terminado este conflito, o valor desta taxa voltou a fixar-se nos 1.200 réis a arroba. Em todo o caso, sobre cada arroba de tabaco ainda acresciam outras taxas (para a alfândega do açúcar, consulado, comboio e obras) e o pagamento de emolumentos aos oficiais da alfândega, perfazendo um total de 1.679 réis em meados do século. ${ }^{20}$ Esta carga fiscal era sentida como pesada pelos importadores, razão pela qual representações por eles feitas à Junta foram colhidas

17 Esta preocupação em conciliar interesses metropolitanos com interesses coloniais é comum a outras monarquias que também encontraram no tabaco uma fonte de financiamento relevante, muito embora esta conciliação tenha conhecido distintos graus de sucesso. Sobre este assunto, veja-se PRICE, Jacob M., «Tobacco Use and Tobacco Taxation: A Battle of Interests in Early Modern Europe» in GOODMAN, Jordan; SHERRATT, Andrew; LOVEJOY, Paul E. (eds.), Consuming Habits: Drugs in History and Anthropology, Londres, Routledge, 1995, pp. 165-185.

18 NARDI, O Fumo Brasileiro, pp. 106-107.

19 NARDI, O Fumo Brasileiro, pp. 112-113.

20 NARDI, O Fumo Brasileiro, pp. 127-128. 
pelo poder político, traduzindo-se nalgumas alterações introduzidas no final da década de 1720. Entre elas contam-se o aumento da tara de duas para quatro libras por arroba, a redução para metade dos direitos de entrada a cobrar sobre o tabaco de inferior qualidade e a extensão do prazo de pagamento das taxas aduaneiras. ${ }^{21}$ Em 1751, nova alteração na pauta aduaneira promoveu a reexportação de tabaco, determinando que por cada partida apenas metade pagaria direitos de saída, medida que indirectamente também favorecia os importadores. ${ }^{22}$

Não obstante este acomodar de interesses dos agentes mercantis envolvidos na trazida de tabaco brasileiro, as taxas alfandegárias permaneceram elevadas, contribuindo para o quadro genérico de constrangimentos em que se realizava a actividade, a acrescentar ao estanco e ao seu regime de aquisição de tabaco a preços administrados. A estes constrangimentos institucionais juntavam-se ainda outros de natureza económica, como o frete marítimo e as flutuações da procura dos mercados externos, também eles com impacte na sua actividade económica. Refira-se, aliás, que o novo quadro normativo definido para a Alfândega do Tabaco em 1751 visou estabelecer um valor máximo do frete para proteger os agentes e o movimento das suas alfândegas. ${ }^{23}$

A passagem para o regime de exploração privada do monopólio doméstico trouxe também mudanças com implicações para o exercício da actividade dos importadores. Por um lado, se é certo que a execução do contrato continuou a desenrolar-se dentro das normas definidas pelo Estado, a transferência para os privados deixou-lhes margem de manobra para que pudessem organizar alguns segmentos do negócio em total liberdade. Nesses termos, certas opções de gestão dos consórcios vieram competir com a actividade de trazida do tabaco, tópico a desenvolver nas secções seguintes. Por outro lado, a passagem para a administração indirecta encerrou o livre acesso do mercado da Espanha continental aos importadores, o que veio a suceder logo em $1702 .{ }^{24}$ Doravante, este

21 Decretos de 18 de Setembro de 1728 e 18 de Julho de 1729; NARDI, O Fumo Brasileiro, p. 127.

22 Veja-se o Regimento da Alfândega do Tabaco (1751), publicado em Systema ou Colecção dos Regimentos Reais, cap. 2, $\S 5$. Veja-se também NARDI, O Fumo Brasileiro, pp. 130-131.

23 Regimento da Alfândega do Tabaco (1751), Systema ou Colecção dos Regimentos Reais, cap. 7, §1.

24 Este privilégio foi uma das condições negociadas pelo castelhano Pedro Gómez para o seu triénio de 1702-1704, tendo perdurado nas décadas seguintes (ANTT, JAT, maço 5, condição 2. ${ }^{a}$ do contrato). Note-se que a produção de tabaco no império espanhol era insuficiente, razão pela qual se recorreu desde cedo à importação de tabaco brasileiro, via Lisboa, e de tabaco da Virgínia para colmatar as necessidades do estanco metropolitano. Sobre este assunto, vejam-se, RODRÍGUEZ GORDILLO, J. M., «El Abastecimento de Tabaco del Brasil a las Reales Fábricas de Sevilla en el Primer Tercio del Siglo XVIII» in XIV Coloquio de Historia Canario-Americana, Las Palmas de Gran Canaria, 2000, pp.1871-1887; RODRÍGUEZ GORDILLO, J. M., «La Influencia del Tabaco de Virginia en la Configuración del Mercado Español en la Segunda Mitad del Siglo XVII», VILA VILAR, E. e LACUEVA MUÑOZ, J. J. (eds.), Mirando las dos Orillas: 
mercado passou a ser exclusivo dos contratadores-gerais, decisão que gerou inúmeros protestos dos agentes mercantis. ${ }^{25}$

Definidos os termos essenciais da moldura normativa e institucional em que se inscrevia a exploração do estanco, a secção seguinte analisa os dados dos Livros da Entrada de tabaco para a fábrica nos anos de 1710-1737.

\section{A repartição do fornecimento ao estanco}

Os oito Livros de Entrada aqui explorados registam a aquisição da matéria-prima para transformação na fábrica de Lisboa e nas demais manufacturas reais e cobrem os anos de 1710-1712, 1716-1733 e 1735-1737. ${ }^{26}$ Vale a pena notar que estes livros eram parte integrante da escrituração obrigatória da fábrica, de acordo com parâmetros definidos pela monarquia, com o objectivo de controlar a quantidade de tabaco metida no estanco. Estavam a cargo de um oficial da Junta, que tinha por obrigação registar esses movimentos diários, quer o estanco estivesse cedido por meio de contratos a consórcios mercantis ou sob administração directa. No caso vertente, estes livros dizem respeito aos contratos encabeçados por Manuel de Aguilar (1710-1712), Pedro Gómez (1716-1718), António Ribeiro (1719-1721), Willem de Bruijn (1722-1727), Gabriel António Gómez (1728-1733) e Manuel Monteiro da Rocha (1735-1737).

Neste período, os contratadores adquiriram uma média anual de 1,1 milhões de libras de tabaco em bruto para transformação na fábrica, cerca de 25,5 por cento do total das importações estimadas de tabaco (quadro 1 e quadro 6, em anexo). ${ }^{27}$ Do remanescente, parte maioritária seguiria para reexportação e uma outra acabaria por se deteriorar no Armazém Grande e ser queimada. Na falta de livros de alfândega, os números da reexportação para esta cronologia não podem ser determinados, mas o quinquénio de 1756-1760 serve de referente à distribuição relativa do conjunto das importações entre o

Intercambios Mercantiles, Sociales y Culturales entre Andalucía y América, Sevilha, Fundación Buenas Letras, 2012, pp. 227-250; e GORDILLO, J. Rodríguez, «El Mercantilismo Español en la Encrucijada: El Tabaco de Virginia en el Estanco Español en el Siglo XVIII (1701-1760)», in LUXÁN, Santiago de (dir.), Política y Hacienda del Tabaco en los Imperios Ibéricos, Siglos XVII-XIX, Madrid, Centro de Estudios Políticos e Constitucionales, 2014, pp. 47-89.

25 Pelo seu efeito lesivo, o fim do exclusivo do mercado da Espanha continental foi uma reivindicação constante dos importadores (NARDI, O Fumo Brasileiro, p.127).

26 No desenho institucional do estanco, a fábrica de Lisboa tinha como função adquirir a totalidade da matéria-prima destinada ao mercado doméstico, que depois se distribuía pelas demais fábricas do reino: a do Porto, criada em 1702, e as das ilhas (Madeira, São Miguel e Terceira). Veja-se SALVADO, «Estanco do Tabaco em Portugal», pp 140-141.

27 Para uma avaliação do consumo per capita do tabaco no mercado doméstico, veja-se neste livro, COSTA, Leonor Freire e SALVADO, João Paulo, «Consumo, Inovação Organizacional e Fiscalidade do Tabaco em Portugal, 1701-1803». 
estanco, a reexportação e as sobras. Nessa altura, o estanco tinha um peso relativo de 29,98 por cento, as reexportações 54,19 e as sobras 15,83 por cento. ${ }^{28}$

Quadro 1 - Importação e aquisição de tabaco para o estanco, 1710-1737

(em libras)

\begin{tabular}{|l|l|l|l|}
\hline Anos & Importação & \multicolumn{1}{|c|}{ Estanco } & \multicolumn{1}{c|}{ Saldo } \\
\hline 1710 & 0 & 1.175 .940 & -1.175 .940 \\
\hline 1711 & 576.000 & 528.952 & 47.048 \\
\hline 1712 & 7.718 .048 & 1.451 .697 & 6.266 .351 \\
\hline 1716 & 3.733 .088 & 1.146 .109 & 2.586 .979 \\
\hline 1717 & 1.785 .120 & 938.053 & 847.067 \\
\hline 1718 & 4.334 .880 & 817.690 & 3.517 .190 \\
\hline 1719 & 5.136 .800 & 1.061 .253 & 4.075 .547 \\
\hline 1720 & 7.971 .552 & 1.401 .713 & 6.569 .839 \\
\hline 1721 & 8.305 .856 & 1.135 .044 & 7.170 .812 \\
\hline 1722 & 5.385 .568 & 1.273 .887 & 4.111 .681 \\
\hline 1723 & 3.997 .888 & 1.003 .221 & 2.994 .667 \\
\hline 1724 & 0 & 1.161 .254 & -1.161 .254 \\
\hline 1725 & 7.237 .184 & 996.456 & 6.240 .728 \\
\hline 1726 & 7.924 .384 & 1.238 .009 & 6.686 .375 \\
\hline 1727 & 7.028 .576 & 1.293 .060 & 5.735 .516 \\
\hline 1728 & 2.659 .392 & 1.302 .116 & 1.357 .276 \\
\hline 1729 & 3.733 .056 & 1.009 .827 & 2.723 .229 \\
\hline 1730 & 5.610 .944 & 1.416 .082 & 4.194 .862 \\
\hline 1731 & 4.945 .952 & 893.500 & 4.052 .452 \\
\hline 1732 & 926.816 & 1.099 .943 & -173.127 \\
\hline 1733 & 4.455 .296 & 1.558 .804 & 2.896 .492 \\
\hline 1735 & 2.667 .200 & 1.153 .002 & 1.514 .198 \\
\hline 1736 & 4.752 .256 & 1.166 .277 & 3.585 .979 \\
\hline 1737 & 5.769 .152 & 916.760 & 4.852 .392 \\
\hline Total & 106.655 .008 & 27.138 .649 & 79.516 .359 \\
\hline Média & 4.443 .959 & 1.130 .777 & 3.313 .182 \\
\hline & & \\
\hline
\end{tabular}

Fontes: Importações estimadas (NARDI, O Fumo Brasileiro, pp. 366-367 e 370-371); Estanco (ANTT, JAT, livs. 2, 6-7, 13, 17, 19 e 21).

Se a matéria-prima adquirida para o estanco representava uma média anual de 25,45 por cento do total das importações para os anos de 1710-1737, há que recordar que os

28 Cálculos efectuados a partir de NARDI, O Fumo Brasileiro, p. 367. 
consórcios controlariam efectivamente uma fatia maior das importações, que oscilaria entre 43,45 por cento e 47,05 por cento, em virtude do contrato da Espanha que absorvia, de acordo com os dados da Junta da Administração do Tabaco, entre 800.000 a 960.000 libras por ano. ${ }^{29}$ Não restam dúvidas de que aqui se reuniam as condições para que esta reserva de mercado dos contratadores-gerais impactasse na actividade dos importadores, sobretudo quando os consórcios se mostravam mais proactivos e capitalizados.

A sistematização dos movimentos diários de aquisição do tabaco organizada pelos operadores permite surpreender o número de fornecedores e a repartição do fornecimento. Ao longo dos oito triénios em observação, os contratadores-gerais compraram rolos de tabaco a 232 negociantes (quadro 2). Uma rápida análise do perfil deste universo revela a participação maioritária de portugueses $(78,45$ por cento), responsáveis por 93 por cento do tabaco em rolo vendido ao estanco. Minoritário, o fornecimento de estrangeiros, a quem o exclusivo vedava o comércio directo com as possessões coloniais, terá várias explicações possíveis que, todavia, não foi possível despistar caso a caso. Por um lado, pode esconder reexportadores, a quem o contratador comprou tabaco à revelia, ao abrigo dos seus privilégios, e por outro, pode remeter para indivíduos naturalizados ou descendentes de estrangeiros já nascidos no reino.

Já o perfil socioeconómico dos 232 importadores é tarefa que está para lá do escopo deste texto. A observação dos vinte maiores fornecedores permite, todavia, uma aproximação a alguns denominadores comuns deste grupo. Eram pequenos e médios negociantes radicados na praça de Lisboa, à excepção de três deles que integravam o círculo restrito dos grandes negociantes (Manuel Velho da Costa, Jerónimo Lobo Guimarães e José Damásio) (quadro 7, em anexo). Esta constatação vem confirmar a ideia que nesta cronologia também a importação de tabaco, tal como a contratação do estanco, não mobilizou a elite mercantil de Lisboa. ${ }^{30}$ Por seu turno, considerando o número de anos em que este universo mais restrito forneceu tabaco ao estanco, é possível constatar a existência de realidades diversas. Colhem-se indícios de especialização, reflectida em fornecimentos regulares e continuados ao longo dos anos por onze negociantes, que teriam na trazida de tabaco uma área relevante da sua actividade. Os restantes figuram como fornecedores ocasionais, ainda que em quantidades apreciáveis, o que pode ter uma

29 NARDI, O Fumo Brasileiro, p. 126. Consulta da Junta da Administração do Tabaco de 24 de Abril de 1700 (ANTT, JAT, maço 5).

30 SALVADO, «O Estanco do Tabaco em Portugal». 
miríade de explicações, só possível de despistar caso a caso. Uma delas prende-se com estratégias dos consórcios mercantis que exploraram o monopólio do tabaco, como se verá na secção seguinte.

Quadro 2 - Repartição do fornecimento de tabaco ao contrato-geral, 1710-1737 (em libras)

\begin{tabular}{|l|l|l|l|l|l|l|}
\hline Intervalos & 1 & $\%$ & $\%$ acu. & 2 & $\%$ & $\%$ acu. \\
\hline$>1.000 .000$ & 4 & 1,72 & 1,72 & 15.640 .092 & 58,45 & 58,45 \\
\hline $250.000-999.999$ & 13 & 5,60 & 7,32 & 5.922 .859 & 22,13 & 80,58 \\
\hline $50.000-249.999$ & 35 & 15,09 & 22,41 & 3.289 .462 & 12,29 & 92,87 \\
\hline $10.000-49.999$ & 66 & 28,45 & 50,86 & 1.516 .511 & 5,67 & 98,54 \\
\hline $2.000-9.999$ & 65 & 28,02 & 78,88 & 341.623 & 1,28 & 99,82 \\
\hline $400-1.999$ & 39 & 16,81 & 95,69 & 45.944 & 0,17 & 99,99 \\
\hline$<400$ & 10 & 3,31 & 100,00 & 2.232 & 0,01 & 100,00 \\
\hline Total & 232 & 100,00 & & 26.758 .723 & 100,00 & \\
\hline
\end{tabular}

Legenda: 1. Número de fornecedores ao estanco. 2. Quantidade de tabaco fornecida ao estanco.

Fontes: ANTT, JAT, livs. 2, 6-7, 13, 17, 19 e 21.

A repartição do fornecimento por intervalos permite identificar uma estrutura concentrada, na qual quatro indivíduos forneceram quase 59 por cento do tabaco que em vinte e quatro anos deu entrada na Fábrica de Lisboa (quadro 2). Esta tendência para a concentração no topo convive com a fragmentação na base, se atentarmos ao elevado número de negociantes nos últimos três escalões, o que se conforma com a ideia que este negócio ainda atraía muitos indivíduos com pouco capital. Isto parece prenunciar que, no decurso deste arco temporal, se operou uma viragem no sentido da concentração dos negócios nesta actividade, já notada para outros contextos geográficos. A desagregação destes dados pelos triénios correspondentes aos contratos gerais revela a dimensão da concentração e o momento em que se concretizou a viragem (quadro 3). 
Quadro 3 - Fornecedores dos contratos-gerais, 1710-1737

\begin{tabular}{|c|c|c|c|c|c|c|c|}
\hline \multicolumn{2}{|c|}{$\mathbf{1 7 1 0 - 1 7 1 2}$} & \multicolumn{2}{|c|}{$\mathbf{1 7 1 6 - 1 7 1 8}$} & \multicolumn{2}{c|}{ 1719-1721 } & \multicolumn{2}{c|}{ 1722-1724 } \\
\hline 1 & 2 & 1 & 2 & 1 & 2 & 1 & 2 \\
\hline 75 & 25,96 & 68 & 18,49 & 94 & 10,17 & 41 & 68,59 \\
\hline
\end{tabular}

\begin{tabular}{|c|c|c|c|c|c|c|c|}
\hline \multicolumn{1}{|c|}{ 1725-1727 } & \multicolumn{2}{|c|}{$\mathbf{1 7 2 8 - 1 7 3 0}$} & \multicolumn{2}{|c|}{$\mathbf{1 7 3 1 - 1 7 3 3}$} & \multicolumn{2}{|c|}{$\mathbf{1 7 3 5 - 1 7 3 7}$} \\
\hline 1 & 2 & 1 & 2 & 1 & 2 & 1 & 2 \\
\hline 43 & 71,70 & 23 & 94,06 & 11 & 89,33 & 27 & 86,30 \\
\hline
\end{tabular}

Legenda: 1. Número de fornecedores ao contrato; 2. Quantidade de tabaco fornecido pelo maior fornecedor (em \%).

Fontes: as citadas no quadro 2.

Em perspectiva comparada, os dados do primeiro (1710-1712) e do último contrato (1735-1737) falam de uma diminuição em dois terços do número de fornecedores, bem como de uma concentração do fornecimento, com início no contrato de 1722-1724. Com a ressalva que estes dados reportam apenas os fornecedores ao estanco doméstico, cuja representatividade no conjunto das importações correspondia a pouco mais de um quarto do total das importações, parece razoável admitir que também em Lisboa se verificou a tendência assinalada por Price e Clemens quanto à diminuição do número de agentes envolvidos na importação de tabaco. ${ }^{31}$ A multiplicação de falências entre os importadores portugueses de que se encontra rasto na Junta da Administração do Tabaco na década de 1720 poderá ser já um sintoma desta tendência. Contudo, a estabilidade e solidez das casas mercantis que negociavam em tabaco, fenómeno que acompanha a concentração dos negócios nos portos ingleses, não está replicada no caso português. Pelo contrário, a tendência registada no quadro 3 coexiste com um fenómeno de volatilidade entre os maiores importadores, que se entrevê do facto de os três maiores terem mantido actividade não mais do que sete anos consecutivos (quadro 7, em anexo). Como explicar estas duas tendências, aparentemente opostas, concentração e volatilidade? Com recurso a uma outra tipologia de fontes, a secção seguinte discute em que medida as estratégias de gestão dos consórcios mercantis que exploraram o estanco impactaram na configuração do grupo dos importadores.

\section{A integração vertical do fornecimento}

A reconstituição e análise da composição dos consórcios fornecem a lente necessária para observar as realidades que se escondem por detrás do fenómeno de concentração da

31 PRICE e CLEMENS, «A Revolution of Scale in Overseas Trade». 
importação de tabaco detectado a partir de 1722. A deslocação do enfoque analítico para os indivíduos e, neste caso, para as opções de gestão tomadas aquando da exploração do estanco do tabaco permite surpreender fenómenos que os registos da fábrica de Lisboa não esclarecem. Sob este ponto de vista, o consórcio de De Bruijn e Companhia, que deteve o monopólio entre 1722 e 1727, introduziu uma inovação organizativa que, sendo seguida pelos consórcios seguintes, produziu impactes duradouros na actividade de importação e nos seus agentes. Os termos dessa inovação são, todavia, inseparáveis das características deste consórcio que exige um exame mais detalhado.

Ao fim de nove anos de fixação em Lisboa e de uma bem-sucedida carreira enquanto negociantes de grosso trato, os holandeses Willem de Bruijn e Paulo Cloots estenderam a sua actividade à contratação de rendas reais, escolhendo para o efeito o primeiro contrato da monarquia - o estanco do tabaco. Fizeram-no associados a Arnaldo van Zeller, um português descendente de negociantes holandeses, e com o intuito expresso de acumularem fortuna, antes de regressarem a Amsterdão, de onde eram originários. ${ }^{32}$ Para fazer face aos exigentes investimentos do contrato-geral, De Bruijn e Cloots contavam com o crédito que podiam mobilizar junto da casa banqueira de Jean Baptiste e Paulo Jacomo Cloots, de quem Paulo Cloots era sobrinho. A esta indiscutível vantagem, os holandeses juntavam ainda a experiência que vinham acumulando desde 1713 sobre o comércio luso-atlântico e sobre as modalidades de agência através das quais o exclusivo colonial português, que os impedia de aceder directamente ao império, podia ser contornado. Entre elas, estava o recurso a parceiros, sócios minoritários ou testas-deferro, portugueses, por intermédio de quem realizavam os seus negócios. ${ }^{33}$ De Bruijn e Cloots contavam ainda com uma sólida formação mercantil, adquirida no comptoir da casa Cloots de Amsterdão, e uma sofisticada organização contabilística, como se depreende do arquivo que deixaram. ${ }^{34}$

Tal como definido desde 1702 pela monarquia, a execução do contrato decompunha-se em três segmentos de negócio: a aquisição da matéria-prima, transformação do tabaco em pó e folha e a distribuição. Foi no primeiro segmento que o consórcio holandês inovou de forma decisiva, ao avançar para a integração vertical do fornecimento do tabaco em bruto.

32 Sobre este consórcio, veja-se neste livro, MIRANDA, Susana Münch, «Risco e Expectativas no Monopólio Português do Tabaco, 1722-1727».

33 ANTUNES, Cátia; MIRANDA, Susana Münch; SALVADO, João Paulo, «The Resources of Others: Dutch Exploitation of European Expansion and Empires, 1570-1800», in Tijdschrift voor Geschiedenis, vol. 131, n. ${ }^{\circ} 3$, 2018, pp. 501-521.

$34 \mathrm{O}$ estudo deste arquivo está em curso por uma equipa formada Cátia Antunes (Leiden University), Susana Münch Miranda (CIDEHUS, Universidade de Évora) e João Paulo Salvado (CIDEHUS, Universidade de Évora). 
O modelo de gestão que puseram em prática é, na verdade, indiciador de uma estratégia proactiva que visava estender os seus interesses ao sector da importação, onde esperavam vir a alcançar uma posição dominante. Enquanto estrangeiros, e para contornar o exclusivo que lhes vedava o comércio directo com o Brasil, este consórcio recorreu a António Gomes Figueiró, em nome de quem o tabaco era importado. Cristão-novo, negociante de pequena-média dimensão da praça de Lisboa, Figueiró tinha alguma experiência na actividade de trazida de tabaco brasileiro e havia integrado, conjuntamente com o seu irmão Manuel, o consórcio do triénio de 1719-1721. ${ }^{35}$ Para além de testa-deferro, Figueiró foi também chamado para exercer funções de administrador da fábrica de Lisboa, o que é revelador da intenção dos holandeses em fazer dele parte interessada no sucesso do contrato.

Nos dois triénios do consórcio holandês, Figueiró foi responsável pelo fornecimento de quase cinco milhões de libras de tabaco, que representaram 70 por cento do total da matéria-prima que entrou na fábrica de Lisboa (quadro 4). ${ }^{36}$ Aos preços administrados do estanco, esta mercadoria valeria 646.400 .000 de réis. Nem a quantidade nem o valor relativo assim movimentados são compatíveis com a posição que Figueiró ocupava na hierarquia da praça Lisboa, donde parece evidente que estes investimentos feitos na trazida de tabaco foram realizados pelo consórcio holandês.

\section{Quadro 4 - Tabaco fornecido ao estanco por António Gomes Figueiró, 1722-1727}

\begin{tabular}{|l|l|l|}
\hline Triénio & Libras & Réis \\
\hline $1722-1724$ & 2.420 .849 & 314.930 .900 \\
\hline $1725-1727$ & 2.549 .219 & 331.497 .080 \\
\hline Total & 4.970 .068 & 646.427 .980 \\
\hline \multicolumn{2}{|l}{ Fonte: ANTT, JAT, livs. 2 e 7}
\end{tabular}

Este volume e escala configuram inequivocamente uma integração vertical do fornecimento da matéria-prima que, no caso vertente, visava a prossecução de vários objectivos. Em primeiro lugar, ao eliminar o intermediário na importação, os holandeses pretendiam chamar a si a margem bruta da trazida do tabaco, estratégia que, se é certo que exigia investimentos mais alargados de capital, lhes permitia obter uma renda adicional. Em segundo lugar, esta estratégia também seria relevante para obstar aos

35 O consórcio de 1719-1721 foi encabeçado por António Ribeiro (ANTT, JAT, maço 52, Decreto de 14 de Agosto de 1718).

36 Vejam-se também os quadros 3 e 7. 
problemas de opportunistic behavior e de hold-up power dos importadores, que seriam tanto mais relevantes tendo em conta a escala e as exigências de um monopólio de venda à escala nacional. Por último, com a extensão dos seus interesses à importação, De Bruijn e Cloots visaram adquirir uma posição dominante no negócio da reexportação de tabaco. Isso mesmo se depreende dos 3,1 milhões de libras de tabaco que reexportaram, maioritariamente para Itália e Espanha, no decurso dos seis anos em que exploraram o estanco (quadro 5). Com o tabaco que forneceram à fábrica por intermédio de António Gomes Figueiró, este consórcio movimentou cerca de oito milhões de libras, o equivalente a 25,34 por cento do total das importações estimadas por Nardi neste arco temporal.

\section{Quadro 5 - Tabaco reexportado por De Bruijin e Cloots, 1722-1727}

\begin{tabular}{|l|l|l|}
\hline Destinos & Libras & \% \\
\hline Itália (Génova, Livorno, Nápoles e Messina) & 1.521 .120 & 48,21 \\
\hline Espanha (Cádis, Alicante, Corunha, Sevilha, Barcelona) & 1.018 .560 & 32,28 \\
\hline Alemanha (Hamburgo) & 411.456 & 13,04 \\
\hline Holanda (Amesterdão) & 76.224 & 2,42 \\
\hline Não identificado & 59.520 & 1,89 \\
\hline França (La Rochelle, Baiona) & 46.464 & 1,47 \\
\hline África ocidental (Mina) & 16.832 & 0,53 \\
\hline Inglaterra (Londres) & 4.032 & 0,13 \\
\hline Norte de África (Mazagão) & 960 & 0,03 \\
\hline Total & 3.155 .168 & 100,00 \\
\hline
\end{tabular}

Fonte: ANTT, JAT, liv. 243

De Bruijn e Cloots vieram, pois, demonstrar que o estanco doméstico podia ser utilizado para explorar em simultâneo negócios conexos ou paralelos, o que poderia ter implicações na captação de outras rendas. Desde que a sociedade fosse capaz de reunir o capital financeiro e o know-how necessário, a integração da cadeia de abastecimento servia não só para abastecer o estanco, mas também para uma exploração mais eficiente do mercado reservado da Espanha ou de outros mercados europeus de colocação do tabaco. O mesmo era válido na exploração do privilégio relativo ao navio anual de licença. Navegando fora do regime de frotas, estes navios prometiam lucros adicionais, obtidos não só pela trazida de tabaco, mas sobretudo por meio da colocação de produtos manufacturados no Brasil em situação de vantagem competitiva. 
Terminado o último triénio de De Bruijn e Cloots, os consórcios subsequentes perceberam as vantagens da integração da cadeia de abastecimento e a ela recorreram também, numa escala até superior, como se depreende do quadro 3. A sua concretização fez-se associando um negociante experiente no comércio de tabaco à sociedade gestora do estanco, isto é, fazendo dele parte interessada no sucesso da execução do contrato. Por seu intermédio, o consórcio não só garantia o know-how necessário, como também por ele canalizava o investimento de capital para operar este segmento do negócio. João Leite Ferreira foi chamado a integrar os dois triénios de Gabriel António Gómez (1728-1733), enquanto o consórcio liderado por Manuel Monteiro da Rocha (1735-1737), se veio a apoiar num dos grandes negociantes de Lisboa, Manuel Velho da Costa. ${ }^{37}$ Para o fornecedor maioritário/sócio de cada contrato, esta estratégia permitia-lhe ter acesso preferencial ao abastecimento do mercado doméstico, bem como ao mercado da Espanha, o que lhe dava vantagens competitivas inegáveis face aos demais operadores. Mesmo depois de 1737, há evidência empírica suficiente que comprova que a integração do abastecimento foi prosseguida pelos consórcios subsequentes. Sobretudo aqueles mais musculados do ponto de vista financeiro como os de Feliciano Velho Oldenberg (17411752) e os de Duarte Lopes Rosa (1756-1764) reuniram as condições para controlar o fornecimento da matéria-prima.

Nestes termos, não surpreende que a volatilidade dos maiores fornecedores surja associada à concentração do negócio da importação: à mudança de consórcio, correspondia também a substituição do fornecedor dominante. Longe de resultar da competência económica e financeira das casas mercantis tabaqueiras, como sucedeu em Inglaterra, no caso vertente a concentração dos negócios foi simultaneamente consequência de um arranjo institucional, o estanco, e de uma opção empresarial introduzida pelos consórcios que o exploraram. É difícil, pois, reconhecer nestas tendências um fenómeno de especialização em torno da trazida de tabaco brasileiro.

\section{Conclusão}

A base empírica aqui carreada não deixa margem para dúvidas relativamente à existência de um fenómeno de reconfiguração do universo dos importadores de tabaco em Portugal na primeira metade do século XVIII. À semelhança do que sucedeu em Inglaterra, também em Portugal se assistiu à concentração dos negócios nesta área de actividade,

37 Cf. quadro 7, em anexo. 
com início na década de 1720. Todavia, essa tendência ocorreu aqui em simultâneo com um fenómeno de rápida substituição dos maiores importadores. A coexistência destas duas tendências opostas remete, pois, para vectores explicativos distintos daqueles avançados por Price e Clemens para a Inglaterra. Se no caso inglês a concentração se explica por uma revolução de escala que levou à consolidação das grandes casas tabaqueiras, para Portugal a exploração privada do estanco do tabaco é um factor explicativo determinante. Remontando a 1702, esta modalidade de administração indirecta continha já alguns ingredientes para condicionar a actividade de importação, em virtude dos privilégios acordados aos consórcios que o exploravam, mormente com a definição do mercado reservado da Espanha. Foi, todavia, depois de 1722, com a adopção da integração vertical do fornecimento pelos consórcios que o seu impacte sobre a importação de tabaco e os seus agentes se intensificou. Seja pelo recurso a um testa-deferro ou a um importador preferencial, certo é que as condições de concorrência entre os importadores se alteraram e se traduziram numa redução do número de importadores. No contexto de sucessão de consórcios, a volatilidade dos maiores importadores é uma decorrência desta opção empresarial. Se outras variáveis explicativas merecem ainda investigação, como a dinâmica dos preços no produtor ou os custos de transporte marítimo, há pelo menos que reconhecer que o estanco doméstico do tabaco condicionou o comércio de importação. 
Quadro 6 - Tabaco em rolo adquirido para a fábrica de Lisboa ${ }^{38} / 1710-1712,1716-1733,1735-1737$

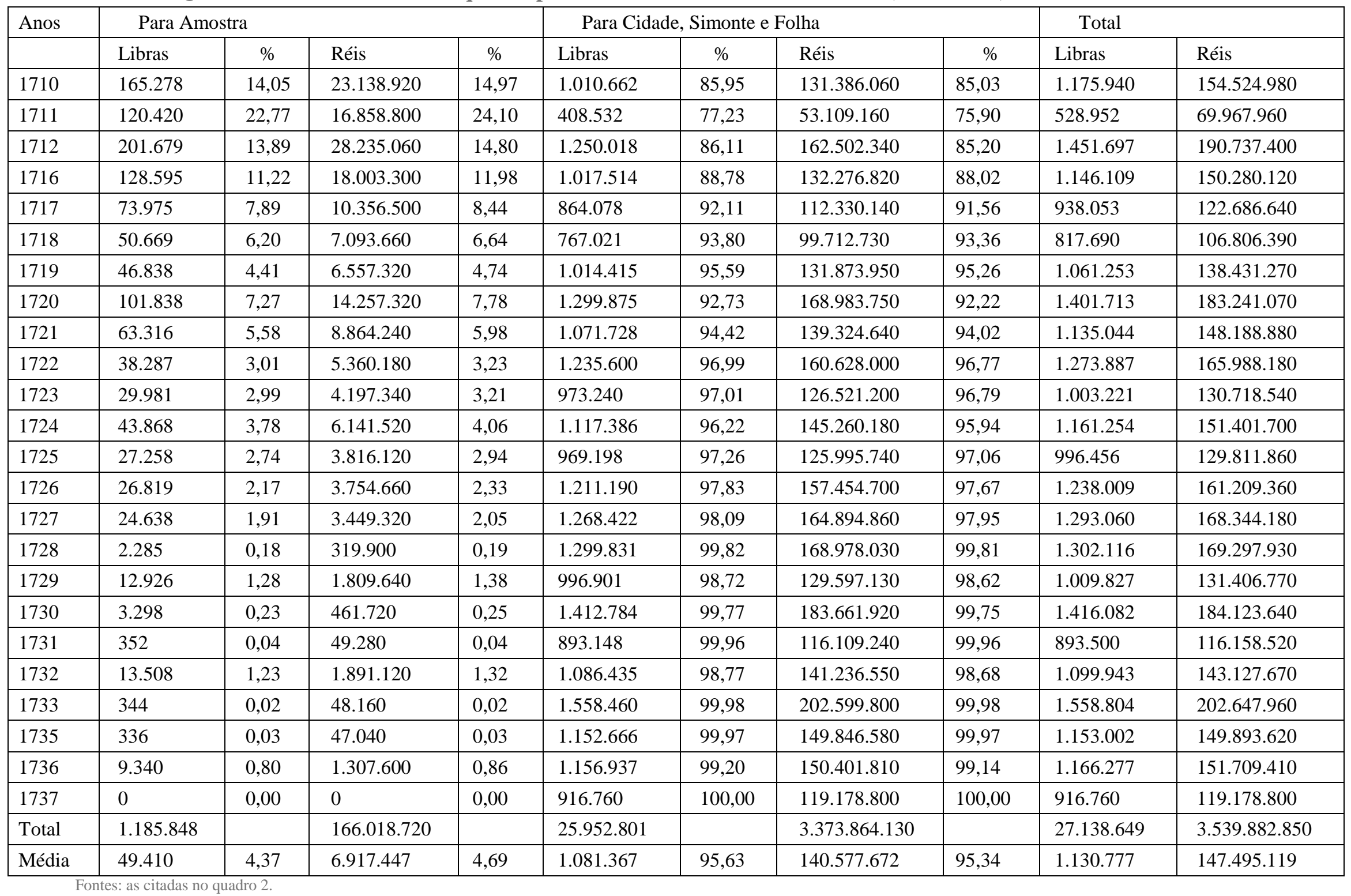

38 Na fábrica de Lisboa produziam-se três tipos de tabaco em pó: amostra, cidade e simonte. O tabaco de primeira qualidade destinado a produzir amostra comprava-se ao importador a 140 réis a libra, enquanto o tabaco destinado às demais qualidades de pó e folha adquiria-se a 130 réis a libra, conforme o tabelamento fixado pelo decreto de 4 de Março de 1699. 
Quadro 7 - Os vinte maiores fornecedores de tabaco ao estanco 1710-1712, 1716-1733, 1735-1737 (em libras)

\begin{tabular}{|l|l|l|l|l|}
\hline \multicolumn{1}{|c|}{ Fornecedores } & 1 & 2 & \multicolumn{1}{|c|}{3} & 4 \\
\hline João Leite Ferreira & 6.694 .597 & 6 & 1.115 .766 & 870.297 .610 \\
\hline António Gomes Figueiró & 4.971 .202 & 7 & 710.172 & 646.575 .400 \\
\hline Manuel Velho da Costa & 2.800 .422 & 3 & 933.474 & 364.054 .860 \\
\hline Jerónimo Lobo Guimarães & 1.173 .871 & 21 & 55.899 & 152.603 .230 \\
\hline José Damásio & 892.432 & 17 & 52.496 & 116.016 .160 \\
\hline Manuel de Almeida Soares & 831.730 & 3 & 277.243 & 108.124 .900 \\
\hline Domingos Pires Bandeira & 659.818 & 15 & 43.988 & 85.776 .340 \\
\hline Pedro Gómez & 552.070 & 5 & 110.414 & 71.769 .100 \\
\hline António Marques Silva & 436.642 & 11 & 39.695 & 56.763 .460 \\
\hline Francisco Luís Saião & 365.117 & 12 & 30.426 & 47.465 .210 \\
\hline Leonardo de Brito de Barros & 365.100 & 2 & 182.550 & 47.463 .000 \\
\hline Domingos da Cunha e Freitas & 342.242 & 10 & 34.224 & 44.491 .460 \\
\hline Miguel da Silva Pereira & 333.684 & 18 & 18.538 & 43.378 .920 \\
\hline José Rodrigues de Figueiredo & 321.699 & 16 & 20.106 & 41.820 .870 \\
\hline Gabriel Lopes Pinheiro & 276.139 & 5 & 55.228 & 35.898 .070 \\
\hline Custódio de Almeida Pacheco & 273.485 & 6 & 45.581 & 35.553 .050 \\
\hline José Ferreira da Silva & 272.701 & 14 & 19.479 & 35.451 .130 \\
\hline Francisco Duarte da Silva & 197.676 & 12 & 16.473 & 25.697 .880 \\
\hline Francisco Belaguarda & 188.517 & 10 & 18.852 & 24.507 .210 \\
\hline Francisco de Faria da Silva & 181.522 & 2 & 90.761 & 23.597 .860 \\
\hline Total & 22.130 .666 & & & 2.877 .305 .720 \\
\hline
\end{tabular}

Legenda: 1. Quantidade de tabaco fornecida; 2. Número de anos que forneceram; 3. Média anual do tabaco fornecido; 4. Valor do tabaco fornecido (em réis).

Fontes: as citadas no quadro 2. 